\title{
Imaging Signs in Spontaneous Intracranial Hypotension: Prevalence and Relationship to CSF Pressure
}

\author{
(D).G. Kranz, (D)T.P. Tanpitukpongse, (D) K.R. Choudhury, (D)T.J. Amrhein, and (D). Gray
}

\begin{abstract}
BACKGROUND AND PURPOSE: Patients with spontaneous intracranial hypotension often exhibit low CSF pressure and changes on brain MR imaging and/or evidence of CSF leak on myelography. We investigated whether individual imaging signs of spontaneous intracranial hypotension correlate with measured CSF pressure and how frequently these 2 markers of spontaneous intracranial hypotension were concordant.
\end{abstract}

MATERIALS AND METHODS: We performed a retrospective, cross-sectional study of 99 subjects with spontaneous intracranial hypotension. Prevalence of brain and myelographic imaging signs of spontaneous intracranial hypotension was recorded. CSF pressure among subjects with or without individual imaging signs was compared by using a 2-tailed $t$ test and ANOVA. Concordance between low CSF pressure $\left(\leq 6 \mathrm{~cm} \mathrm{H}_{2} \mathrm{O}\right)$ and imaging was defined as the presence of the sign in a subject with low CSF pressure or absence of the sign when pressure was not low.

RESULTS: Dural enhancement, brain sagging, and venous distension sign were present in $83 \%, 61 \%$, and $75 \%$ of subjects, respectively, and myelographic evidence of CSF leak was seen in 55\%. Marginal correlations between CSF pressure and brain sagging $(P=.046)$ and the venous distension sign $(P=.047)$ were found. Dural enhancement and myelographic evidence of leak were not significantly correlated with CSF pressure. Rates of concordance between imaging signs and low CSF pressure were generally low, ranging from $39 \%$ to $55 \%$.

CONCLUSIONS: Brain and myelographic signs of spontaneous intracranial hypotension correlate poorly with CSF pressure. These findings reinforce the need to base the diagnosis of spontaneous intracranial hypotension on multiple diagnostic criteria and suggest the presence of patient-specific variables that influence CSF pressure in these individuals.

ABBREVIATIONS: $\mathrm{P}_{\mathrm{CSF}}=\mathrm{CSF}$ pressure; $\mathrm{SIH}=$ spontaneous intracranial hypotension

ow CSF pressure $\left(\mathrm{P}_{\mathrm{CSF}}\right)$ is a well-known feature of spontane-ous intracranial hypotension (SIH) and is one of several diagnostic criteria for the disorder. ${ }^{1,2}$ The fact that SIH is categorized by the International Classification of Headache Disorders, 3rd edition, as a "headache attributed to low cerebrospinal fluid pressure" ${ }^{2}$ underlines the historical strength of the association between SIH and abnormally low pressure.

Given this association, it would be expected that low CSF pres-

Received October 19, 2015; accepted after revision November 27.

From the Department of Radiology, Duke University Medical Center, Durham, North Carolina.

Paper previously presented in part at: American Society of Neuroradiology Annua Meeting and the Foundation of the ASNR Symposium, April 25-30, 2015; Chicago, Illinois.

Please address correspondence to Peter G. Kranz, MD, Department of Radiology, DUMC Box 3808, Duke University Medical Center, Durham, NC 27710; e-mail: pe-

ter.kranz@duke.edu; @PeterGKranz

http://dx.doi.org/10.3174/ajnr.A4689 sure would also be associated with other diagnostic criteria of SIH, including typical brain imaging findings and the presence of CSF leak on myelography. ${ }^{1}$ There is some evidence to the contrary, however. Previous investigators have recognized that patients with brain imaging findings of SIH or myelographic evidence of CSF leak may not exhibit low CSF pressure. ${ }^{3,4}$ This observation would seem to call into question whether low CSF pressure is the fundamental cause of SIH and has prompted the alternate hypothesis that SIH is actually primarily a disorder of low CSF volume rather than low pressure. ${ }^{5}$ To our knowledge, the frequency of discordance between imaging and CSF pressure and, by inference, the likelihood of this alternate hypothesis have not been previously explored.

The purpose of this investigation is to describe the prevalence of brain imaging and myelographic signs of SIH from a large retrospective series of patients with confirmed SIH and to determine the correlation between these imaging signs and CSF pres- 
Table 1: Diagnostic criteria for SIH from Schievink et al ${ }^{1}$

\section{Criteria}

A) Orthostatic headache
B) The presence of at least 1 of the following:
1) Low opening pressure ( $\leq 60 \mathrm{~mm} \mathrm{H}_{2} \mathrm{O}$ )
2) Sustained improvement of symptoms after epidural
blood patching
3) Demonstration of an active spinal CSF leak
4) Cranial MRI changes of intracranial hypotension (eg, brain
sagging or pachymeningeal enhancement)
C) No recent history of dural puncture
D) Not attributable to another disorder

sure measurements, with a particular focus on reporting how commonly imaging signs of SIH and low CSF pressure are concordant or discordant.

\section{MATERIALS AND METHODS}

This investigation is a retrospective cross-sectional study of patients with SIH treated at our institution between January 2006 and October 2014. The investigation was approved by our local institutional review board and is compliant with Health Insurance Portability and Accountability regulations.

\section{Subjects}

Subjects were identified through review of departmental procedure logs of patients evaluated for possible SIH. Standard initial diagnostic work-up for suspected SIH at our institution includes lumbar puncture followed immediately (ie, within 1-3 minutes after contrast injection) by CT myelography of the cervical, thoracic, and lumbar spine. ${ }^{6}$ CSF opening pressure was recorded from this initial evaluation. All pressures were measured with the patient in the lateral decubitus position, with legs extended, and resting quietly. Demographic information was recorded from the patient's electronic medical record.

Subjects were included if they satisfied the diagnostic criteria for SIH previously outlined by Schievink et al (Table 1). ${ }^{1}$ Patients were excluded if preprocedural brain MR imaging was not available.

\section{Image Analysis}

Brain MR imaging was reviewed to evaluate imaging findings of SIH. Abnormal dural enhancement was evaluated on postcontrast axial and/or coronal T1-weighted images in subjects with available postcontrast brain imaging. Brain sagging was considered present if downward sloping of the third ventricular floor resulting in descent of the mammillary bodies to the level of the dorsum sella was present on either sagittal T1- or T2-weighted images. A "venous distension" sign was considered present if there was a convex inferior border of the dominant transverse venous sinus at its midportion (approximated by a section containing the lens of the eye) on sagittal T1- or T2-weighted images. ${ }^{7}$ Pituitary hyperemia, another imaging sign reported in association with $\mathrm{SIH},{ }^{8}$ was not assessed in this investigation because it was thought to be too subjective and not a principal sign of the condition.

CT-myelograms were reviewed to evaluate the presence of a CSF leak, defined by the presence of contrast outside of the thecal sac in the epidural space. If present, CSF leaks were further classified as either high-flow leaks, denoted by the presence of a pool of epidural contrast extending over $>1$ vertebral segment, or lowflow leaks, in which contrast leakage did not extend over $>1$ vertebral segment. ${ }^{9}$

Initial image review was performed by a board-certified radiologist in the second year of a neuroradiology fellowship. Equivocal or borderline cases were reviewed by a second board-certified radiologist who holds a Certificate of Added Qualification in neuroradiology and has 12 years' experience interpreting brain MR imaging, including extensive experience in evaluating patients with SIH.

Concordance or discordance of the individual brain imaging signs with low CSF pressure (defined as $\mathrm{P}_{\mathrm{CSF}}$ of $\leq 6 \mathrm{~cm} \mathrm{H}_{2} \mathrm{O}$ ) was also assessed. Individual signs were considered concordant if the sign was present in a subject with low CSF pressure or absent when the pressure was $>6 \mathrm{~cm} \mathrm{H}_{2} \mathrm{O}$. Conversely, a sign was considered discordant if it was present but the subject's CSF pressure was $>6 \mathrm{~cm} \mathrm{H}_{2} \mathrm{O}$ or if the sign was absent but the subject's CSF pressure was low.

\section{Statistical Analysis}

Descriptive statistics regarding the prevalence of individual imaging signs and the concordance/discordance of those signs with CSF pressure were calculated. For individual brain MR imaging signs, differences in CSF pressure between groups with or without the sign present were compared by using a 2-tailed $t$ test. For individual leak patterns on CT myelography (ie, no leak, highflow leaks, and low-flow leaks), CSF pressure between groups was compared by using ANOVA. Additionally, CSF pressure in the group showing any evidence of leak (either high-flow or lowflow) was compared with the group with no leak by using a 2 -tailed $t$ test. Analysis was performed by using $\mathrm{R}$ statistical and computing software, Version 3.0.2 (http://www.r-project.org). For all comparisons, a $P$ value $<.05$ was considered statistically significant.

\section{RESULTS}

A total of 106 patients with SIH were identified. Of these, 7 were excluded due to the absence of any available preprocedural brain MR imaging, with a final study population of 99 subjects ( 33 men, 66 women). Of these subjects with available preprocedural brain imaging, 6 brain MRIs were performed without contrast; the remaining studies (93 subjects, 94\%) were performed with and without contrast. The mean age for the final study population was $47.8 \pm 13.4$ years.

\section{Prevalence of Imaging Signs}

Of the 93 subjects with available postcontrast brain MR images, $83 \%$ (77 subjects) showed abnormal dural enhancement. Among all 99 subjects, 61\% (60 subjects) showed evidence of brain sagging and $75 \%$ (74 subjects) showed a venous distension sign.

Of all 99 subjects, $93 \%$ (92 subjects) showed at least 1 of the 3 imaging signs. All 3 signs were present in $43 \%$ of subjects; 2 signs, in 33\%; 1 sign, in 16\%; and zero signs (ie, brain MR imaging negative for signs of SIH), in 7\%. Of the 6 subjects with noncontrast images only, 5 showed at least 1 imaging sign (ie, brain sagging or venous distension sign); the remaining patient had normal brain imaging findings but met the criteria for the diagnosis 

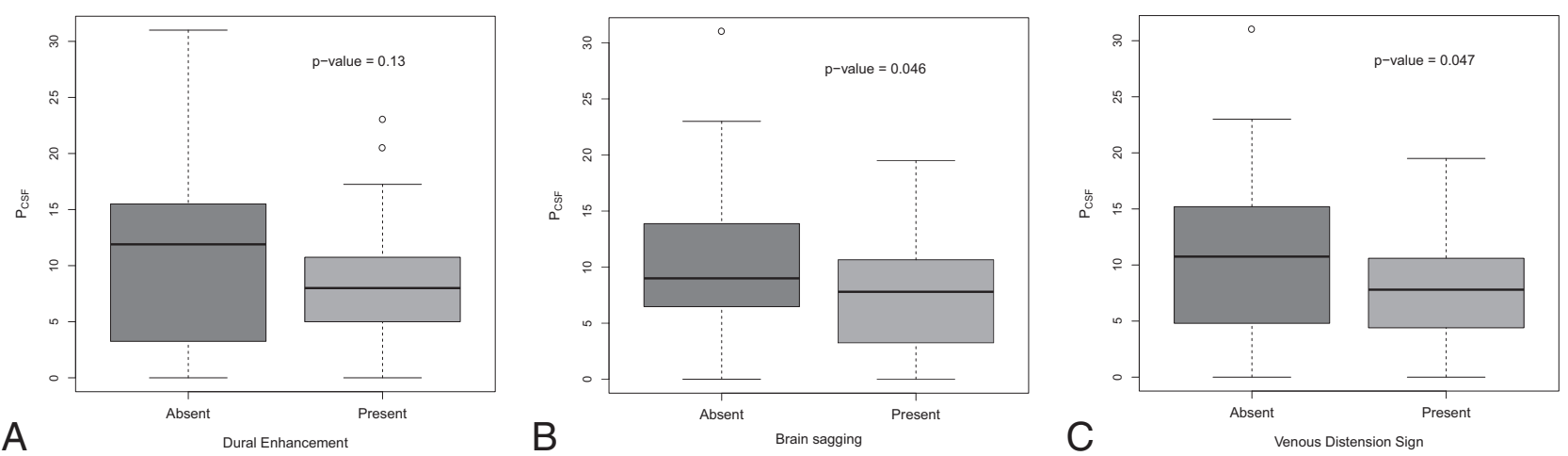

FIG 1. Box-and-whisker plots comparing $\mathrm{P}_{\mathrm{CSF}}\left(\mathrm{cm} \mathrm{H}_{2} \mathrm{O}\right)$ with the presence or absence of individual brain imaging signs of $\mathrm{SIH}$.

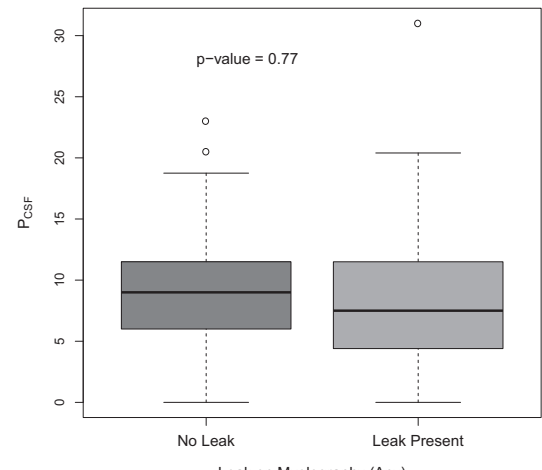

A

Leak on Myelography (Any)

FIG 2. Box-and-whisker plots comparing $\mathrm{P}_{\mathrm{CSF}}\left(\mathrm{cm} \mathrm{H}_{2} \mathrm{O}\right)$ with the presence or absence of various myelographic patterns in $\mathrm{SIH}$.

of SIH by having a CSF pressure of $0 \mathrm{~cm} \mathrm{H}_{2} \mathrm{O}$ and evidence of a high-flow leak on myelography.

On CT myelography, $55 \%$ of subjects showed a leak of any type. Of these subjects with a leak, most (46 subjects, $85 \%$ ) had a high-flow leak, and the remainder (8 subjects, 15\%) had a lowflow leak.

\section{Correlation of Imaging Signs and CSF Pressure}

The distribution of CSF pressure in subjects with and without individual brain imaging signs is shown in Fig 1. For all signs, there was substantial overlap in the distribution of CSF pressures between groups.

No significant difference in CSF pressure was observed between subjects with and without dural enhancement (mean $\mathrm{P}_{\mathrm{CSF}}$, $7.8 \pm 4.8$ versus $11.3 \pm 8.4 ; P=.13$ ). Marginally significant differences in CSF pressure were seen for brain sagging (mean $\mathrm{P}_{\mathrm{CSF}}$, $7.4+4.9$ versus $10.1+7.0 ; P=.046$ ) and for the venous distension sign (mean $\mathrm{P}_{\mathrm{CSF}}, 7.5+4.7$ versus $11.1+8.1 ; P=.047$ ).

The distribution of CSF pressure in subjects with various myelographic leak types is shown in Fig 2. As with brain imaging, there was substantial overlap of CSF pressures between groups. When all patients with any subtype of leak (high-flow or lowflow) were considered together, there was no difference in CSF pressure for patients with leak versus without leak (mean $\mathrm{P}_{\mathrm{CSF}}$, $8.3 \pm 6.2$ versus $8.6 \pm 5.5 ; P=.77$ ). Furthermore, when individual subtypes of leaks were analyzed separately, again no difference in CSF pressure was observed between groups (mean $\mathrm{P}_{\mathrm{CSF}}, 8.6 \pm$ signs, the sign was absent despite the finding of low pressure in at least some cases.

\section{DISCUSSION}

Spinal CSF leaks in SIH, which can be detected by myelography in some cases, cause loss of CSF volume, which some investigators believe results in the changes seen on brain imaging. ${ }^{10,11}$ Given the known relationship between pressure and volume in a closed system, one would expect that these imaging signs of SIH would also be correlated with low CSF pressure, another common finding in SIH. To the contrary, however, our investigation shows that while the presence of $\geq 1$ brain imaging sign is relatively common in patients with SIH, there is weak correlation between individual brain or myelographic imaging signs and a patient's CSF pressure. As a result, discordance between the expected imaging signs and the finding of low CSF pressure is routinely encountered.

This discordance indicates that the imaging findings associated with SIH are not uniformly accompanied by a low-pressure state. Furthermore, it reinforces the need to pursue the diagnosis by using a combination of CSF pressure measurement, brain imaging, and spinal imaging rather than any single test when the diagnosis is suspected.

Our investigation is not the first to describe the variability of CSF pressure and imaging findings in patients with SIH. ${ }^{12}$ Mokri $^{5}$ previously reported a case series of patients with SIH who demonstrated discordant pressure and imaging and suggested that decreased CSF volume rather than decreased pressure was a more 
Table 2: Prevalence of imaging signs and concordance with low $\mathbf{P}_{\mathrm{CSF}}{ }^{a}$

\begin{tabular}{|c|c|c|c|c|c|c|c|c|}
\hline & & & & & \multicolumn{4}{|c|}{ Discordant Sign and $\mathrm{P}_{\mathrm{CSF}}$} \\
\hline & \multicolumn{2}{|c|}{$\begin{array}{c}\text { Overall } \\
\text { Prevalence }\end{array}$} & \multicolumn{2}{|c|}{$\begin{array}{l}\text { Concordant } \\
\text { Sign and } \mathrm{P}_{\mathrm{CSF}}\end{array}$} & \multicolumn{2}{|c|}{$\begin{array}{c}\text { Sign Absent, } \\
P_{\mathrm{CSF}} \leq 6\end{array}$} & \multicolumn{2}{|c|}{$\begin{array}{c}\text { Sign Present, } \\
\mathrm{P}_{\mathrm{CSF}}>6\end{array}$} \\
\hline & $\%$ & No./Total & $\%$ & No./Total & $\%$ & No./Total & $\%$ & No./Total \\
\hline Dural enhancement & 83 & $77 / 93$ & 39 & $36 / 93$ & 5 & $5 / 93$ & 56 & $52 / 93$ \\
\hline Brain sagging & 61 & $60 / 99$ & 55 & $54 / 99$ & 9 & $9 / 99$ & 36 & $36 / 99$ \\
\hline Venous distension sign & 75 & $75 / 99$ & 42 & $42 / 99$ & 8 & $8 / 99$ & 49 & $49 / 99$ \\
\hline Leak on myelogram & 55 & $54 / 99$ & 55 & $54 / 99$ & 12 & $12 / 99$ & 33 & $33 / 99$ \\
\hline
\end{tabular}

${ }^{a}$ Concordance is defined as the presence of the imaging sign when $\mathrm{P}_{\mathrm{CSF}}$ is low $\left(\leq 6 \mathrm{~cm} \mathrm{H} \mathrm{H}_{2} \mathrm{O}\right)$ or absence of the sign when $\mathrm{P}_{\mathrm{CSF}}$ is not low.

appropriate conception of the disease. Since then, other authors have made similar observations, though predominantly in single case reports or small case series. ${ }^{13-15}$ Our data, however, confirm that this variability is common in a large proportion of patients with the disease, rather than in a small subset.

Despite previous reports on this discordance between symptoms and CSF pressure, the concept that low CSF pressure (ie, $\leq 6 \mathrm{~cm} \mathrm{H}_{2} \mathrm{O}$ ) is the fundamental pathology underpinning $\mathrm{SIH}$ remains entrenched in both the literature and professional societies. For example, the International Classification of Headache Disorders, 3rd edition ${ }^{2}$ published in 2013 classifies SIH as "headache attributed to low cerebrospinal fluid pressure." Similarly, a review published in 2015 states that "a decrease in CSF pressure defines spontaneous intracranial hypotension."16 In our experience, these definitions lead to confusion among clinicians seeking to evaluate patients for the condition, often leading to the misconception that CSF pressure measurement alone is sufficient to diagnose or exclude SIH.

Having established that discordance between imaging (which likely principally reflects CSF volume) and CSF pressure is common in $\mathrm{SIH}$, one must next consider why this seemingly paradoxical state occurs, because a loss in CSF volume would be expected to result in decreased CSF pressure. To answer this question, it is useful to briefly consider normal CSF physiology. In the steady-state, CSF pressure is greater than systemic venous pressure, a fact that permits reabsorption of CSF at the level of the arachnoid granulations. ${ }^{17}$ Maintenance of this steady-state CSF pressure occurs via balancing of CSF production and absorption. ${ }^{17}$ Thus, if CSF volume decreases and CSF pressure falls below venous pressure, CSF absorption will decrease; this decrease allows CSF volume to re-accumulate and restore normal CSF pressure, a process termed "dynamic equilibrium." ${ }^{18}$ It is possible, however, to disrupt the homeostatic mechanisms that maintain a constant CSF pressure if the buffering capacity of the system is overwhelmed. ${ }^{17}$

On the basis of our data, it is clear that some patients with CSF leaks are able to maintain the steady-state CSF pressure while others are not, though the ability to maintain the CSF pressure does not necessarily prevent headache in these patients. Furthermore, it seems that this ability to maintain CSF pressure is not solely a function of a slower rate of CSF leakage because we observed no difference in CSF pressures between patients who had evidence of a high-flow CSF leak and those with no leak seen. These observations suggest 2 conclusions: First, that headache in patients with SIH is not primarily determined by low CSF pressure; and second, compensatory mechanisms exist in some indi- viduals that help maintain CSF pressure despite active CSF volume loss.

One potential compensatory mechanism that may vary from person to person is compliance of the thecal sac, which may be influenced by body habitus or dilation of epidural veins. For example, in a recent investigation, Tain et $\mathrm{al}^{19} \mathrm{dem}-$ onstrated that the compliance of the spinal canal was less in patients with obesity with idiopathic intracranial hypertension (pseudotumor cerebri) than in healthy controls, noting that MR imaging of the thecal sac showed a reduced cross-sectional area of the spinal CSF spaces in these patients. ${ }^{19,20}$ In SIH, dilation of the epidural venous plexus has been observed in some cases, ${ }^{21}$ which would reduce cross-sectional area of the spinal canal, thereby compensating for CSF volume loss and increasing CSF pressure, in a manner analogous to pseudotumor cerebri. Moreover, cervical venous dilation is known to change between supine and upright posture in healthy individuals but has been observed to demonstrate person-to-person variability, ${ }^{22}$ a finding that may be more significant in the setting of orthostatic changes in CSF pressure associated with SIH. These compensatory mechanisms would share in common the ability to, at least partially, preserve the overall volume within the enclosed craniospinal canal, allowing CSF pressure to be maintained despite decreased CSF volume due to a spinal fluid leak. In so doing, these proposed mechanisms would satisfy the requirements of the Monro-Kellie hypothesis. ${ }^{11}$ Further investigation into what compensatory mechanisms are engaged in the setting of SIH could potentially help elucidate the underlying physiology of the CSF pressure/volume relationship in these patients and could help guide novel therapies.

Our study has limitations. First, it is possible that there is variability in CSF pressure that could decrease the accuracy of any single pressure measurement. Second, it is possible that our location at a tertiary care center could result in referral bias, leading to an atypical cohort of subjects with $\mathrm{SIH}$, though all subjects satisfied established diagnostic criteria for SIH and most patients had not been treated previously at other centers.

\section{CONCLUSIONS}

The presence of $\geq 1$ brain imaging and myelographic imaging sign of SIH is common in those with the condition, but individual signs generally correlate poorly with CSF pressure measurements. These findings emphasize the need to base the diagnosis of SIH on multiple criteria rather than any single imaging finding or CSF pressure measurement. Furthermore, our results reinforce the 
notion that low CSF pressure is not the only factor that results in the condition and that patient-specific variables may influence the pathophysiology of the disease.

\section{REFERENCES}

1. Schievink WI, Dodick DW, Mokri B, et al. Diagnostic criteria for headache due to spontaneous intracranial hypotension: a perspective. Headache 2011;51:1442-44 CrossRef Medline

2. Headache Classification Committee of the International Headache Society (IHS). The International Classification of Headache Disorders, 3rd edition (beta version). Cephalalgia 2013;33:629-808 CrossRef Medline

3. Mokri B, Hunter SF, Atkinson J, et al. Orthostatic headaches caused by CSF leak but with normal CSF pressures. Neurology 1998;51: 786-90 CrossRef Medline

4. Chung SJ, Kim JS, Lee MC. Syndrome of cerebral spinal fluid hypovolemia: clinical and imaging features and outcome. Neurology 2000;55:1321-27 CrossRef Medline

5. Mokri B. Spontaneous cerebrospinal fluid leaks: from intracranial hypotension to cerebrospinal fluid hypovolemia-evolution of a concept. Mayo Clin Proc 1999;74:1113-23 CrossRef Medline

6. Kranz PG, Gray L, Taylor JN. CT-guided epidural blood patching of directly observed or potential leak sites for the targeted treatment of spontaneous intracranial hypotension. AJNR Am J Neuroradiol 2011;32:832-38 CrossRef Medline

7. Farb RI, Forghani R, Lee SK, et al. The venous distension sign: a diagnostic sign of intracranial hypotension at MR imaging of the brain. AJNR Am J Neuroradiol 2007;28:1489-93 CrossRef Medline

8. Alvarez-Linera J, Escribano J, Benito-León J, et al. Pituitary enlargement in patients with intracranial hypotension syndrome. Neurology 2000;55:1895-97 CrossRef Medline

9. Kranz PG, Luetmer PH, Diehn FE, et al. Myelographic techniques for the detection of spinal CSF leaks in spontaneous intracranial hypotension. AJR Am J Roentgenol 2016;206:8-19 CrossRef Medline

10. Fishman RA, Dillon WP. Dural enhancement and cerebral displacement secondary to intracranial hypotension. Neurology 1993;43: 609-11 CrossRef Medline
11. Mokri B. The Monro-Kellie hypothesis: applications in CSF volume depletion. Neurology 2001;56:1746-48 CrossRef Medline

12. Schievink WI. Spontaneous spinal cerebrospinal fluid leaks and intracranial hypotension. JAMA 2006;295:2286-96 CrossRef Medline

13. Schievink WI, Tourje J. Intracranial hypotension without meningeal enhancement on magnetic resonance imaging: case report. J Neurosurg 2000;92:475-77 CrossRef Medline

14. Schoffer KL, Benstead TJ, Grant I. Spontaneous intracranial hypotension in the absence of magnetic resonance imaging abnormalities. Can J Neurol Sci 2002;29:253-57 CrossRef Medline

15. Schievink WI, Maya MM, Louy C. Cranial MRI predicts outcome of spontaneous intracranial hypotension. Neurology 2005;64:1282-84 CrossRef Medline

16. Ducros A, Biousse V. Headache arising from idiopathic changes in CSF pressure. Lancet Neurol 2015;14:655-68 CrossRef Medline

17. Marmarou A, Shulman K, Rosende RM. A nonlinear analysis of the cerebrospinal fluid system and intracranial pressure dynamics. J Neurosurg 1978;48:332-44 CrossRef Medline

18. Ryder HW, Espey FF, Kimbell FD, et al. The mechanism of the change in cerebrospinal fluid pressure following an induced change in the volume of the fluid space. J Lab Clin Med 1953;41:428-35 Medline

19. Tain RW, Bagci AM, Lam BL, et al. Determination of cranio-spinal canal compliance distribution by MRI: methodology and early application in idiopathic intracranial hypertension. J Magn Reson Imaging 2011;34:1397-404 CrossRef Medline

20. Hogan QH, Prost R, Kulier A, et al. Magnetic resonance imaging of cerebrospinal fluid volume and the influence of body habitus and abdominal pressure. Anesthesiology 1996;84:1341-49 CrossRef Medline

21. Yousry I, Förderreuther S, Moriggl B, et al. Cervical MR imaging in postural headache: MR signs and pathophysiological implications. AJNR Am J Neuroradiol 2001;22:1239-50 Medline

22. Alperin N, Lee SH, Sivaramakrishnan A, et al. Quantifying the effect of posture on intracranial physiology in humans by MRI flow studies. J Magn Reson Imaging 2005;22:591-96 CrossRef Medline 